\title{
Numerical Analysis of Plastic Encapsulated Electronic Package Reliability: Viscoelastic Properties of Underfill Resin
}

\author{
Man-Lung Sham ${ }^{1}$, Jang-Kyo Kim ${ }^{1 *}$ and Joo-Hyuk Park ${ }^{2}$ \\ ${ }^{1}$ Department of Mechanical Engineering, Hong Kong University of Science \& Technology \\ Clear Water Bay, Kowloon, Hong Kong \\ ${ }^{2}$ School of Mechanical \& Aerospace Engineering, Sejong University \\ 98 KunJa-Dong, KwangJin-Ku, Seoul 143-747, Korea
}

\begin{abstract}
The reliability and mechanical performance of electronic integrated circuit (IC) package is studied based on the finite element analysis. The flip chip on board (FCOB) package - one of the most current plastic encapsulated IC packages - consists of a die, solders, a printed circuit board and underfill resin encapsulated between the die and $\mathrm{PCB}$, which is subjected to a typical thermal cycle experienced during the manufacturing process. The effects of viscoelastic properties of underfill resin on mechanical responses and residual stresses of FCOB packages are specifically studied and the results are compared with those obtained for a thermo-elastic underfill resin. The viscoelastic properties of underfill resin are characterized using the time-temperature superposition (TTS) technique. Both the rigid and flexible PCB substrates are considered.

It is found that the elastic model underestimates significantly both the thermal stress and the accumulated creep strain in the solder joints, whereas it overestimates the stress concentrations in the underfill fillet around the die corner than the viscoelastic model. When the package is subjected to an extended dwell time at an elevated temperature, a moderate loss of mechanical coupling between the die and organic substrate is expected due to the relaxation of underfill resin. The implication is that the viscoelastic nature of underfill material should be properly taken into account if the failure of solder joints and the lifetime of the package are to be accurately estimated. This study shed an insight into the importance of correct material property inputs in the design and theoretical studies of plastic packages.
\end{abstract}

Keywords: Reliability, flip chip on board, finite element analysis, viscoelastic properties, underfill resin, flexible substrate

*Corresponding author: Ph) 852-23587207; Fax) 852-23581543; Email) mejkkim@ust.hk 


\section{Introduction}

Amongst many plastic encapsulated integrated circuit (IC) packages, flip-chip-on-board (FCOB) packages have received significant attention in recent years because of many advantages including high number of input/output due to area array interconnection, self alignment during solder reflow, short interconnection, small foot print and low cost solder interconnection technology. A typical flip chip on board (FCOB) package consists of a die, solder bumps, a printed circuit board and underfill resin encapsulated between the die and PCB, as shown in Figure 1 (a). Although the flip chip packages are a matured technology after the development and implementation for over almost four decades, they are not completely free from reliability issues. One of the most challenging and prevailing reliability issues is the failure of solder joints resulting from relative displacements between the die and organic substrate due to mechanical and thermal cyclic fatigue loads. The introduction of underfill that couples the die and organic substrate provides the solder joints with mechanical robustness and enhanced resistance to fatigue. Significant research efforts have been directed toward lifetime prediction of the package based on numerical/analytical methods and experimental verification. In doing so especially the numerical analysis, it is essential to select appropriate assumptions and input data as reliable results depend on proper execution of models. For simplicity, however, almost all previous models for lifetime prediction of solder joints in FCOB have been based on linear-elastic properties of the underfill material. Notwithstanding, it is well known that many polymers display mechanical responses between an elastic solid and a viscous liquid, depending on the temperature and the experimentally chosen time scale. The deformation of polymers is reversible, and is time dependent, being associated with the distortion of polymer chains from their equilibrium conformations through activated segment motion involving rotation about chemical bonds [1]. The phenomenon of viscoelasticity is most obvious for amorphous polymers at temperatures near their glass transition temperatures, $\mathrm{T}_{\mathrm{g}}$. This means that to accurately characterize the polymer for a specific application, experiments need to be performed in the actual working temperature range and the time conditions that the material will likely encounter, especially at high temperatures and bearing low- 
frequency loading. This presents difficulties in performing the tedious measurements over the whole range of temperatures and frequencies.

The Time-Temperature Superposition (TTS) principle has been developed [2] to describe the responses of a polymer over a wide temperature/frequency range based on the observation in that the effect of temperature on material properties is equivalent to that of deformation rate, as these parameters affect the polymer molecular relaxation and rearrangements in a similar manner. The TTS principle allows the properties at a specific temperature over a broad time scale to be estimated using the experimental data, say storage modulus, obtained at different temperatures for a limited frequency range. A master curve of the storage modulus covering a wide frequency response of the material can be established based on the Williams-Landel-Ferry (WLF) relationship:

$$
\log \mathrm{a}_{\mathrm{T}}=\frac{\mathrm{C}_{1}\left(\mathrm{~T}-\mathrm{T}_{\mathrm{S}}\right)}{\mathrm{C}_{2}+\left(\mathrm{T}-\mathrm{T}_{\mathrm{S}}\right)}
$$

where $\mathrm{a}_{\mathrm{T}}$ is the shift factor, $\mathrm{C}_{1}$ and $\mathrm{C}_{2}$ are the constants and $\mathrm{T}_{\mathrm{s}}$ is the reference temperature.

It is shown previously [3-7] that the viscoelastic assumption for polymeric encapsulants made in theoretical studies of electronic packages in general provided better agreement with experimental results obtained from the stress chip measurement than the elastic assumption. Incorrect simplifying assumptions for the material behaviour may often result in erroneous conclusions due to the over- or underestimate of imposed stresses/strains. The viscoelastic nature of the polymeric encapsulant also had a significant implication on the energy release rate and the delamination fracture criterion along the chip-encapsulant interface [7]. As a continuation of our previous work on the characterization of the evolution of thermal residual stresses in polymeric encapsulants [8], this study aims to provide an insight into the importance of correct material property input in the design and theoretical studies of plastic packages. The mechanical responses of FCOB packages with underfill encapsulation are specifically studied based on two distinct assumptions of the thermo-elastic and viscoelastic encapsulants. The stress profiles at some high risk 
failure sites in the package are evaluated and compared between the two models using the finite element method (FEM). In addition, recognizing the increasing popularity of flip chips on flexible circuit carriers for consumer electronics products, the reliabilities of FCOBs with an FR-4 rigid and polyimide flexible substrates are also studied based on the present viscoelastic underfill model. The implications of analytical findings are discussed from the practical reliability viewpoint.

\section{Numerical analysis based on finite element method}

The stress profiles and the creep strains in the FCOB packages with elastic and viscoelastic underfill resin were analysed using the finite element code ANSYS 5.7. The FCOB package model consisted a die, a glass woven fabric reinforced epoxy laminate (FR-4) substrate, solder bumps, an underfill resin and copper studs on the die and substrate. The geometry and the boundary conditions were selected to represent those of the typical FCOB package, as shown in Figure 1 (b). A cross-sectional micrograph is also included, presenting the robust underfilling condition between the die and the substrate. Due to the symmetry, only half the package was adopted for the $2 \mathrm{D}$ model, along with dimensions for the major components. The standoff height was $90 \mu \mathrm{m}$, and the copper stud thickness on the die and substrate were $9.6 \mu \mathrm{m}$ and $29 \mu \mathrm{m}$, respectively. The mesh consisted of 12461 elements and 24463 nodes, and the mesh was refined near the die-underfill-substrate corner where various failure modes likely take place. 8-nodes VISCO 88 elements were employed for the underfill layer, whereas 8-nodes PLANE 183 elements were used for the solder bumps to study the creep behaviour. The rest of the components were modelled using 8-nodes PLANE 82 elements. The entire analysis was performed based on a plain strain assumption. The model was subjected to a thermal excursion from the cure temperature at $165^{\circ} \mathrm{C}$ to ambient and an increase to $150^{\circ} \mathrm{C}$, followed by cooling to $-20^{\circ} \mathrm{C}$, at a ramp rate of $10^{\circ} \mathrm{C} / \mathrm{min}$ and a holding time of $20 \mathrm{~min}$ at the dwell temperature. The details of the temperature profile are shown in Figure 2. The analysis started from the cure temperature of the underfill, i.e. $165^{\circ} \mathrm{C}$, which was considered as the stress-free temperature. The material properties of silicon die and copper are given in Table 1. 
The effects of substrate material and thickness on residual stress distribution in the flip chip packages were also studied. Similar models were developed using $1 \mathrm{~mm}$ thick FR-4 rigid substrate and $100 \mu \mathrm{m}$ thick polyimide flexible substrate, as shown in Figure 3. These models consist of 10089 and 8274 elements for the FR-4 and polyimide substrate, respectively. The packages were subjected to thermal cycles between $40^{\circ} \mathrm{C}$ and $125^{\circ} \mathrm{C}$ with ramp and dwell periods of 15 minutes (Figure 3(b)).

\section{Characterization of the properties of various package components}

The properties of substrates, underfill resins and other package components were characterized to provide inputs for the FE models. The temperature dependent flexural moduli of the FR-4 and flexible substrates were measured using a dynamic mechanical analyzer (Perkin Elmer DMA 7e), and are plotted in Figure 4. At temperatures far below the respective glass transition temperatures, $\mathrm{T}_{\mathrm{g}}$, the flexural moduli of the FR-4 substrate was much higher than those of the polyimide based flexible substrate. However, its flexural modulus dropped significantly at about $120^{\circ} \mathrm{C}$ because of the low $\mathrm{T}_{\mathrm{g}}$ of the FR-4 substrate. In contrast, the flexible substrate showed only a small change in modulus at around $60^{\circ} \mathrm{C}$, where a secondary transition occurred due to the side-group motions in the polymer [2]. In summary, the mechanical properties of the flexible substrate were more stable over a wider working temperature range than those of the rigid substrate.

The eutectic $63 \mathrm{Pd}-37 \mathrm{Sn}$ solder was considered in this study, whose elastic modulus $(\mathrm{E}(\mathrm{T}))$ varied according to Eq. (2). The time-temperature dependent bilinear elasto-plastic behaviours of the solder are plotted in Figure 5 [9]. The steady-state creep behaviour of the solder followed the sinh law model, Eq. (3) $[10]$

$$
\begin{aligned}
& \mathrm{E}(\mathrm{T})=32000-88 \mathrm{~T}(\mathrm{MPa}) \\
& \mathrm{d} \varepsilon / \mathrm{dt}=\mathrm{C}_{1}\left[\sinh \left(\mathrm{C}_{2} \cdot \sigma\left(\mathrm{MPa}^{-1}\right)\right)\right]_{3}^{\mathrm{C}} \exp \left(-\mathrm{C}_{4} / \mathrm{T}\right)
\end{aligned}
$$

where $\mathrm{t}$ and $\mathrm{T}$ are the time and temperature, and the coefficients $\mathrm{C}_{1}=339.0102(\mathrm{~s}) ; \mathrm{C}_{2}=0.062653\left(\mathrm{MPa}^{-1}\right)$; $\mathrm{C}_{3}=3.3$ and $\mathrm{C}_{4}=6360(\mathrm{~K})$. 
The viscoelastic properties of epoxy-based resin (HYSOL 4527) were characterized by using the same dynamic mechanical analyzer where the storage compliance was obtained for a wide range of frequency at a selected reference temperature as shown in Figure 6. Based on the TTS principle, a shift factor, $\mathrm{a}_{\mathrm{T}}(\mathrm{T})$, was used to horizontally shift the modulus curves at different temperatures based on Eq. (1) to obtain the master relaxation curve of the viscoelastic resin, as plotted in Figure 7. A generalized Maxwell element was employed to model the relaxation modulus, $G(t)$, of the resin:

$$
\mathrm{G}(\mathrm{t})=\mathrm{G}_{\infty}+\sum_{1}^{\mathrm{n}} \mathrm{G}_{\mathrm{i}} \mathrm{e}^{\left(-\mathrm{t} / \tau_{\mathrm{i}}\right)}
$$

where $t$ is the relaxation time, $G_{\infty}$ is the equilibrium modulus, $G_{i}$ and $\tau_{i}$ are the modulus and reduced time constants of each Maxwell element; and $n$ is the total number of Maxwell elements ( $n=7$ in this study). The shift factors were calculated for different temperatures using the software built in the DMA analyzer (Perkin Elmer DMA 7e), and are and plotted in Figure 8. It is suggested that the WLF equation is valid over a range of temperature, typically $\mathrm{T}_{\mathrm{g}} \pm 50^{\circ} \mathrm{C}$. In the present study, two WLF-format equations were necessary to best fit the plots of shift factor with two reference temperatures at $52^{\circ} \mathrm{C}(325 \mathrm{~K})$ and $140^{\circ} \mathrm{C}$ (413K). It may be that the silica fillers incorporated in the underfill resin have different degrees of influence on viscoealstic properties of the underfill resin at different temperature ranges. The input parameters for the VISCO 88 element are summarized in Table 2. In the thermo-elastic model, the temperature dependent moduli of the underfill resin taken at $1 \mathrm{~Hz}$ was chosen to use from the testing temperatures included in this work. The coefficients of thermal expansion (CTE) of the underfill resin at temperatures below and above $\mathrm{T}_{\mathrm{g}}\left(=150^{\circ} \mathrm{C}\right)$ were $\alpha_{1}=28 \mathrm{ppm} /{ }^{\circ} \mathrm{C}$ and $\alpha_{2}=80 \mathrm{ppm} /{ }^{\circ} \mathrm{C}$, respectively.

\section{Results and discussion}

\subsection{Residual Stresses and Creep Strains}

Typical failure modes of FCOB packages, such as fatigue failure of solder joints, underfill resin delamination at various interfaces and fracture of the underfill fillet near the silicon die corner, have been 
reported previously. Therefore, the evaluation of stress profiles was focused for the corner solder-die corner-underfill fillet region. Figure 9 illustrates the general stress distributions at the solder bumps and underfill fillet region near the die corner at $150^{\circ} \mathrm{C}$. Generally higher stress concentrations were predicted in the solder bump based on the viscoelastic model than the elastic model, and the reverse was true for the underfill fillet. This observation was more clearly manifested based on the enlarged profiles as shown in Figures 10 and 11 , where the von Mises stresses in the underfill fillet predicted at $-20^{\circ} \mathrm{C}$ are plotted. The reasons for choosing different temperatures for the solder and underfill fillet were because the accelerated creep rate of eutectic solder increased with increasing temperature, whereas the stress in the underfill fillet increased with decreasing temperature. The chosen temperatures allowed one to evaluate the performances of two package components in the worst cases. There were significant stress concentrations in the solder joints near the solder-copper stud interfacial region below the silicon die (Figure 10). The viscoelastic model predicted higher stress concentrations than in the elastic model. The stress relaxation of polymer was mainly responsible for the reduced mechanical support provided by the underfill resin, which in turn increased the stresses in the solder joints. The stress relaxation takes place through molecular rearrangement and is particularly pronounced at elevated temperatures and for an extended dwell period [8]. The above observation suggests a possibility of earlier failure in the viscoelastic model due to thermocyclic fatigue than in the elastic model. The underestimate of stress concentrations in the elastic model may also mean an overestimate of lifetime in the reliability test, which is considered dangerous from the viewpoints of device design and application.

The importance in considering the relaxation behaviour of underfill resin was further manifested by the stress distributions in the underfill fillet (Figure 11). The stress concentrations at the upper and bottom die corners were much higher in the elastic model than in the viscoelastic model. This is because the changes in modulus with time and temperature were taken into account in the viscoelastic model (Figure 6). Figure 12 also presents creep curves of the cured underfill resin when subjected to three-point bending at a constant load of $5 \mathrm{~N}$. The maximum displacement measured at the loading point increased with increasing 
time, the increment being more prominent at elevated temperatures, exhibiting typical viscoelastic behaviour of polymers. Obviously, one of the most significant anomalies arising from neglecting the inherent viscoelastic behaviour of underfill resin in the elastic model is the overestimate of stress concentrations (Figure 11). A comparison of the stress levels at the bottom die corner between the two models is plotted in Figure 13. The stress level predicted by the elastic model was more than four times higher than the viscoelastic model, which agreed with the conclusions in our previous study on plastic quad flat pack (PQFP) packages [4]. It is also interesting to note that the extent of stress relaxation in the initial step (Stage 1 - Stage 2) was higher than the final step (Stage 7 - Stage 8). A similar phenomenon was reported previously [8], proving that the relaxation took place due to slower structural change of the material in response to a constant temperature to reach the expected equilibrium state (Stage 1 - Stage 2), and such an equilibrium was reached with repeated thermal excursions [Stage 7 - Stage 8].

The accumulated creep strain profiles in the corner solder bump are compared between the two models in Figure 14. In the viscoelastic model, the maximum accumulated creep strain occurred at the outer solder joint edge near the silicon die, and a crack is expected to initiate from this region and propagate toward the bulk solder. Similar results were reported previously [6] with a higher maximum accumulated creep strain in the solder joint predicted by the viscoelastic model. Table 3 compares the maximum accumulated creep strains in the corner solder joint bump predicted by the previous and present studies. The comparison clearly indicates that there was a good agreement between the two studies, and that the elastic model underestimated the accumulated creep strain in the solder, which is consistent with the above observations. This observation has a significant practical implication in that the elastic model may result in a higher risk of unexpected solder joint failure than the viscoelastic model.

\subsection{Effects of Substrate Properties on Residual Stresses}


Apart from the consideration of practical applications, there are a great deal of interests in using FR-4 rigid or flexible substrates due to the disparities in mechanical rigidity. Therefore, the thermo-mechanical responses of these two materials were studied after a given thermal excursion based on the FE analyses. Figure 15 shows the residual stress profiles obtained after four thermal cycles (at Point A in Figure 3 (b)). The dwell temperature at $125^{\circ} \mathrm{C}$ was chosen because the creep rate and the total accumulated creep strain generally increase with temperature close to the melting temperature of the solder at $183^{\circ} \mathrm{C}$ [11]. It is interesting to note that the locations where maximum stress occurred inside the solder bumps were at the solder-copper stud interface of the outermost solder in the rigid FCOB, and near the substrate in the flexible FCOB. The differences in thermo-elastic properties, especially the flexural modulus and CTE, and thickness of substrate material resulted in the above observation. The package made from the rigid FR-4 substrate had a much higher stiffness, and thus the overall deformation under thermal cycles was severely limited. It follows that the stress concentrated at the locations where there were the largest mismatches in CTE, such as near the die-solder interface or substrate-solder interface, as shown in Figure 15 (a). Obviously, the stress along the die surface was proportional to the distance from the axis of symmetry as well as the axial and shears displacements. As a result, the maximum stress occurred in the outermost solder bump. In contrast, the flexible circuit board was more compliant to package deformation. Therefore, the maximum stress occurred in the solder bump near the highly deformed flexible substrate interface instead of the die interface. A similar observation was noticed in the underfill fillet, as shown in Figure 15 (b). The maximum stress occurred at the die corner for the rigid FR-4 package, while the maximum stress in the underfill was found along the flexible substrate.

The maximum shear stress and creep strain determined at the solder joint corner in response to thermal cycles are plotted in Figure 16. There are a few points worth noting: the shaded area in the graphs indicates the initial residual stress due to the thermal shrinkage of underfill resin. The result indicates that improper selection of stress-free temperature would underestimate the final stress and strain levels after thermal loading. Both the shear stress and creep strain were higher in the package with a flexible substrate 
than that with a rigid substrate, except the very early stage of thermal cycles. Especially, the final creep strain in the flexible substrate was 2.7 times higher than that in the FR-4 substrate (Figure 16 (b)). Thence, this study may provide an insight into an early failure of FCOB with flexible substrate after thermal cycling. This also suggests that the expected working environment for the FCOB with a flexible substrate should not be too harsh, or a substrate board with a higher stiffness such as fibre reinforced bimaleimide triazine (BT) substrate should be considered to replace the flexible board. The difference between the peak shear stress/creep strain corresponding to a high temperature and the lowest stress/strain corresponding to a low temperature gradually increased with increasing the number of cycles, and was more pronounced in the flexible substrate than in the rigid substrate. Extensive deformations of the flexible substrate during the thermal excursions were mainly responsible for the higher stress/strains in the flexible substrate at the early stage of thermal cycles, where the shear stresses and the shear creep strains were exaggerated with the increased plastic deformation of the solder material.

\section{Concluding Remarks}

Both the stress profiles and the accumulated creep strains were evaluated using the finite element method (FEM). The reliabilities of FCOBs with an FR-4 rigid and polyimide flexible substrates were studied for the viscoelastic underfill model. The following can be highlighted from this study.

1. The elastic model underestimated the stress level in the solder bump, while it predicted more than five times higher stress concentrations in the underfill fillet around the die corner than the viscoelastic model.

2. The elastic model underestimated the maximum accumulated creep strain in the solder joint, which agreed with a previous study [6].

3. A moderate loss of mechanical coupling between the die and organic substrate is expected at elevated temperatures and for extended periods of dwell time due to the relaxation of underfill. This suggests 
that the lifetime of the solder joint can hardly be determined accurately without considering the viscoelastic behaviour of the underfill resin.

4. The flexible substrate was unable to support the solder joints when there was an extensive thermal excursion which is frequently encountered during the manufacturing process, although the material response was reasonably stable due to its high glass transition temperature.

5. The shear stress and creep strain in the solder were higher in the package made of a flexible substrate. It is important that the residual stresses arising from thermal shrinkage of the underfill resin be considered in the numerical analysis.

\section{Acknowledgements}

The authors wish to thank the Research Grants Council (RGC) of the Hong Kong Special Administrative Region for continuous support of this project. The numerical analysis was performed when the first author (MLS) was a visiting scholar at Sejong University, Korea. Part of the paper has been presented at the Electronic Components Technology Conference 2003 (ECTC2003), which was held in May 2003, New Orleans, USA.

\section{References}

1. Billmeyer, F.R. (1984), Textbook of Polymer Science $3^{\text {rd }}$ Ed. John Wiley \& Sons Pub.

2. Ward, I.M. and Hadley, D.W. (1993), An Introduction to the Mechanical Properties of Solid Polymers, John Wiley \& Sons Pub.

3. Kong, J.W.Y., Kim, J.K. and Yuen, M.M.F. (2003), "Warpage in plastic packages: effects of materials, geometry and process conditions” IEEE Trans. Comp. Packag. Manufac. Technol. Part C. Electr. Packag. Manufac. 26, 245-252.

4. Park, J.H., Kim, J.K., Yuen, M.M.F., Lee, S.W.R., Tong, P. and Chan, P.C.H. (1998), "Thermal stress 
analysis of a PQFP moulding process: comparison of viscoelastic and elastic models", Key Eng. Mater. 145-149, 1127-1132.

5. Yeung, D.T.S. and Yuen, M.M..F. (2001), "Warpage of plastic IC packages as a function of processing conditions", J. Electr. Packag. 123, 268-272.

6. Feustel, F., Wiese, S. and Meusel, E. (2000), "Time-dependent material modeling for finite element analyses of flip chips", in Proc. 50 ${ }^{\text {th }}$ Electronic Components Technologies Conference, pp.1548-1553.

7. Liu, W. and Shi, F.G. (2002), "Effect of the viscoelastic behaviour of molding compounds on crack propagation in IC packages", in Proc. of $52^{\text {nd }}$ Electronic Components Technologies Conference, pp.854-858.

8. Sham, M.L. and Kim, J.K. (2004), "Evolution of residual stresses in modified epoxy resins for electronic packaging applications", Compos. Part A, 35, 537-546.

9. Dutta, I., Gopinath, A. and Marshall, C. (2002), "Underfill constraint effects during thermomechanical cycling of flip chip solder joints”, J Electro. Mater. 41, 253-264.

10. Huang, X., Lee, S.W.R., Yan, C.C. and Hui, S. (2001), "Characterization and Analysis on the Solder Ball Shear Testing Conditions", in Proc. of $51^{\text {st }}$ Electronic Components Technologies Conference, pp.1065-1071.

11. Lau, J.H. and Pao, Y.H. (1997), Solder Joint Reliability of BGA, CSP, Flip Chip and Fine Pitch SMT Assemblies, McGraw-Hill Pub. 
Table 1 Material properties of silicon die and copper

\begin{tabular}{|l|c|c|c|}
\hline & Modulus, GPa & Poisson's ratio & $\mathrm{CTE}, 10^{-6} /{ }^{\circ} \mathrm{C}$ \\
\hline Silicon & 148 & 0.25 & 2.5 \\
\hline Copper & 76 & 0.35 & 17 \\
\hline
\end{tabular}

Table 2 Parameters for the viscoelastic elements

\begin{tabular}{|c|c|c|c|}
\hline \multicolumn{4}{|c|}{ Parameters for fitting the generalized viscoelastic mode } \\
\hline \multicolumn{2}{|c|}{$\mathrm{G}(0)=4.15 \mathrm{GPa}$} & \multicolumn{2}{|c|}{$\mathrm{G}(\infty)=0.269 \mathrm{GPa}$} \\
\hline $\mathrm{G}_{1}$ & $0.0988 \mathrm{GPa}$ & $\tau_{1}$ & 0.000853 \\
\hline $\mathrm{G}_{2}$ & $0.253 \mathrm{GPa}$ & $\tau_{2}$ & 0.011 \\
\hline $\mathrm{G}_{3}$ & $0.592 \mathrm{GPa}$ & $\tau_{3}$ & 107.17 \\
\hline $\mathrm{G}_{4}$ & $1.231 \mathrm{GPa}$ & $\tau_{4}$ & 2.266 \\
\hline $\mathrm{G}_{5}$ & $0.733 \mathrm{GPa}$ & $\tau_{5}$ & 0.197 \\
\hline $\mathrm{G}_{6}$ & $0.129 \mathrm{GPa}$ & $\tau_{6}$ & 2570.52 \\
\hline $\mathrm{G}_{7}$ & $0.848 \mathrm{GPa}$ & $\tau_{7}$ & 13.55 \\
\hline \multicolumn{2}{|c|}{ WLF Fitting 1} & \multicolumn{2}{|c|}{ WLF Fitting 2} \\
\hline \multicolumn{2}{|c|}{$\mathrm{T}_{\mathrm{REF}}=413 \mathrm{~K}$} & \multicolumn{2}{|c|}{$\mathrm{T}_{\mathrm{REF}}=325 \mathrm{~K}$} \\
\hline \multicolumn{2}{|c|}{$\mathrm{C}_{1}=13.32$} & \multicolumn{2}{|c|}{$\mathrm{C}_{1}=4.915$} \\
\hline \multicolumn{2}{|c|}{$\mathrm{C}_{2}=65.20$} & \multicolumn{2}{|c|}{$\mathrm{C}_{2}=279.71$} \\
\hline
\end{tabular}

Table 3 Comparisons of maximum accumulated creep strains in the solder joint.

\begin{tabular}{|c|c|c|c|}
\hline$\Delta \varepsilon_{\mathrm{cr}}$ & Elastic model $\left(\varepsilon_{\mathrm{cr}}^{\text {elastic }}\right)$ & $\begin{array}{c}\text { Viscoelastic model } \\
\left(\varepsilon_{\mathrm{cr}}^{\text {visco }}\right)\end{array}$ & $\varepsilon_{\mathrm{cr}}^{\text {visco }} / \varepsilon_{\mathrm{cr}}^{\text {elastic }}$ \\
\hline Present Study & 0.0048 & 0.0062 & 1.30 \\
\hline Feustel et al. [5] & 0.004 & 0.009 & 2.25 \\
\hline
\end{tabular}




\section{FIGURE CAPTIONS}

Figure 1 Schematic drawing of the flip chip model: (a) Typical flip chip on board (FCOB) package; and (b) schematic of a FCOB package model.

Figure 2 Temperature profile.

Figure 3 (a) Schematic drawings of the models; and (b) Temperature profile of thermal cycles.

Figure 4 Variations of flexural modulus of FR-4 rigid and flexible substrates with temperature by DMA measurement.

Figure 5 Bilinear plastic properties of solder under different temperatures.

Figure 6 Storage modulus of FP4527 plotted against frequency at different temperatures as indicated.

Figure 7 A master curve obtained by plotting the modulus data in Figure 2 and fitting into seven Maxwell elements $\left(\mathrm{T}_{\mathrm{Ref}}=140^{\circ} \mathrm{C}\right)$.

Figure 8 Temperature dependence of shift factor.

Figure 9 Comparison of the von Mises stress distributions in the solder bumps and the underfill resin at $150^{\circ} \mathrm{C}$ : (a) elastic model; and (b) viscoelastic model.

Figure 10 von Mises stress distributions in the corner solder bump at $150^{\circ} \mathrm{C}$.

Figure 11 von Mises stress distributions in underfill fillet at $-20^{\circ} \mathrm{C}$.

Figure 12 Creep in cured underfill resin as a function of time and temperature when subjected to threepoint bending at a constant load.

Figure 13 Comparison of the von Mises stresses in the underfill resin at die corner between the models based on elastic and viscoelastic properties of underfill.

Figure 14 Accumulated creep strain profiles in the corner solder bump at $-20^{\circ} \mathrm{C}$ : (a) elastic model; and (b) viscoelastic model

Figure 15 von Mises stress profile at $125^{\circ} \mathrm{C}$ : (a) within the solder joints; and (b) within the underfill fillets.

Figure 16 Plots of maximum (a) shear stress and (b) creep strain at the solder joint corner as a function of time in response to the thermal cycles. 


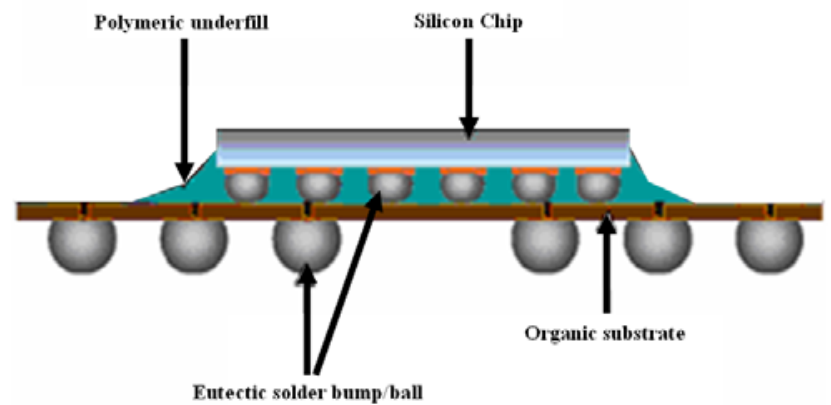

(a)

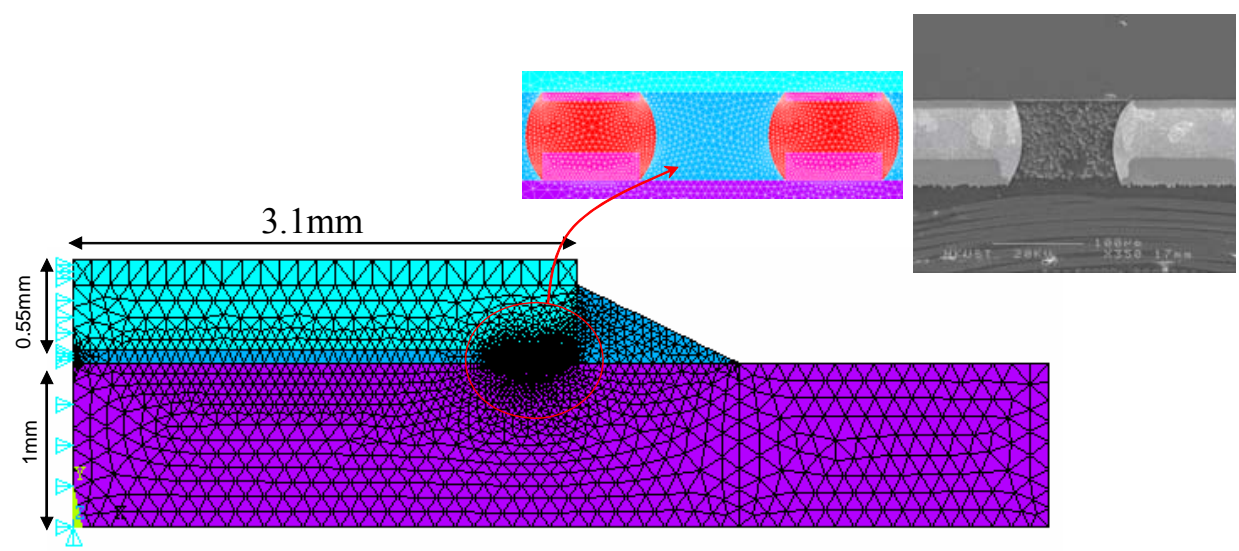

(b)

Figure 1 


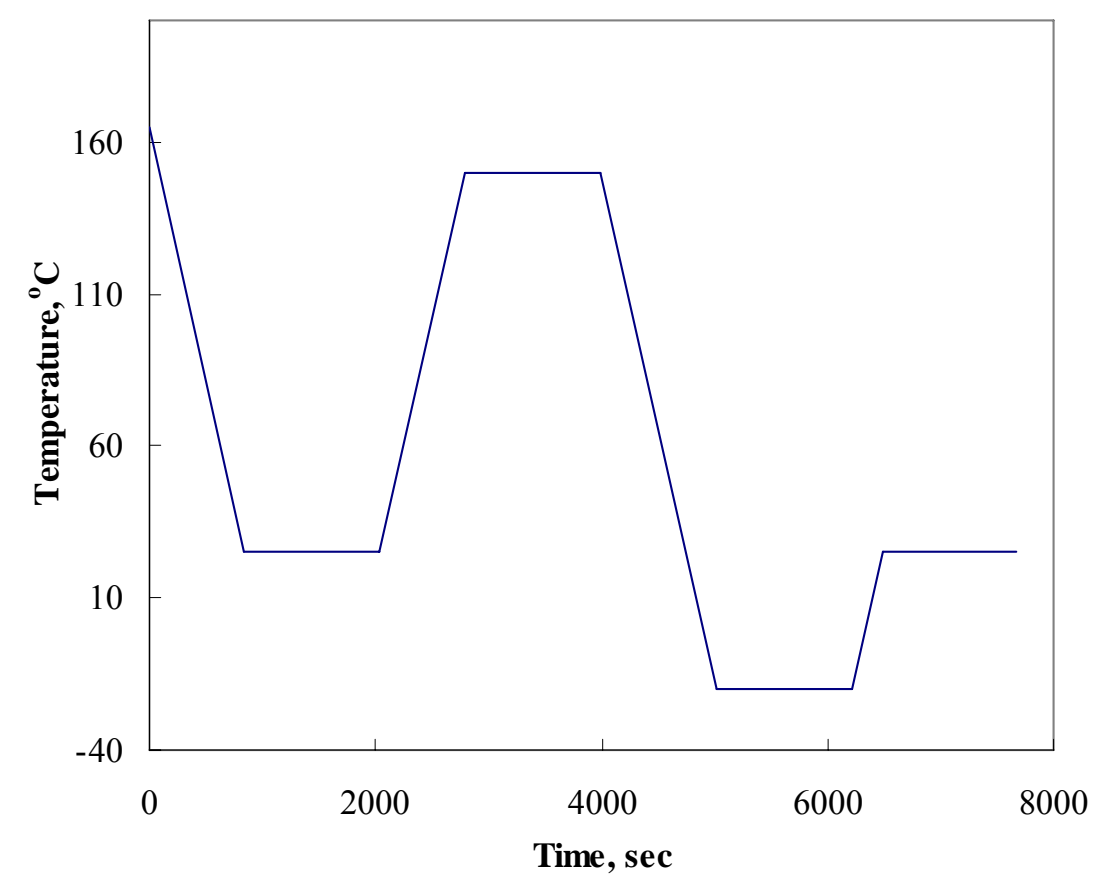

Figure 2 


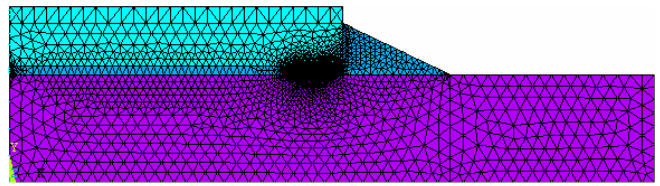

Flip chip on FR-4

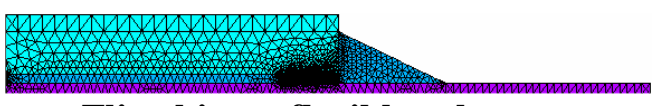

Flip chip on flexible substrate

(a)

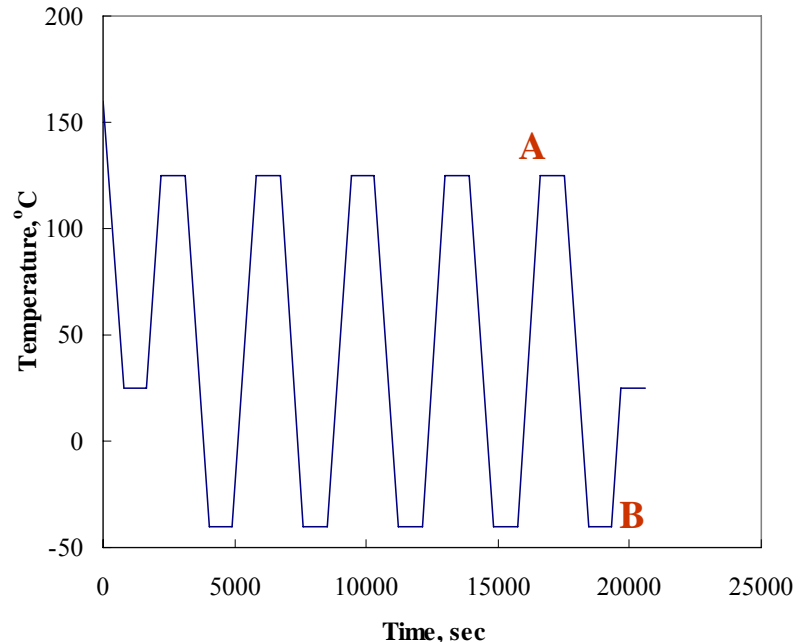

(b)

Figure 3 


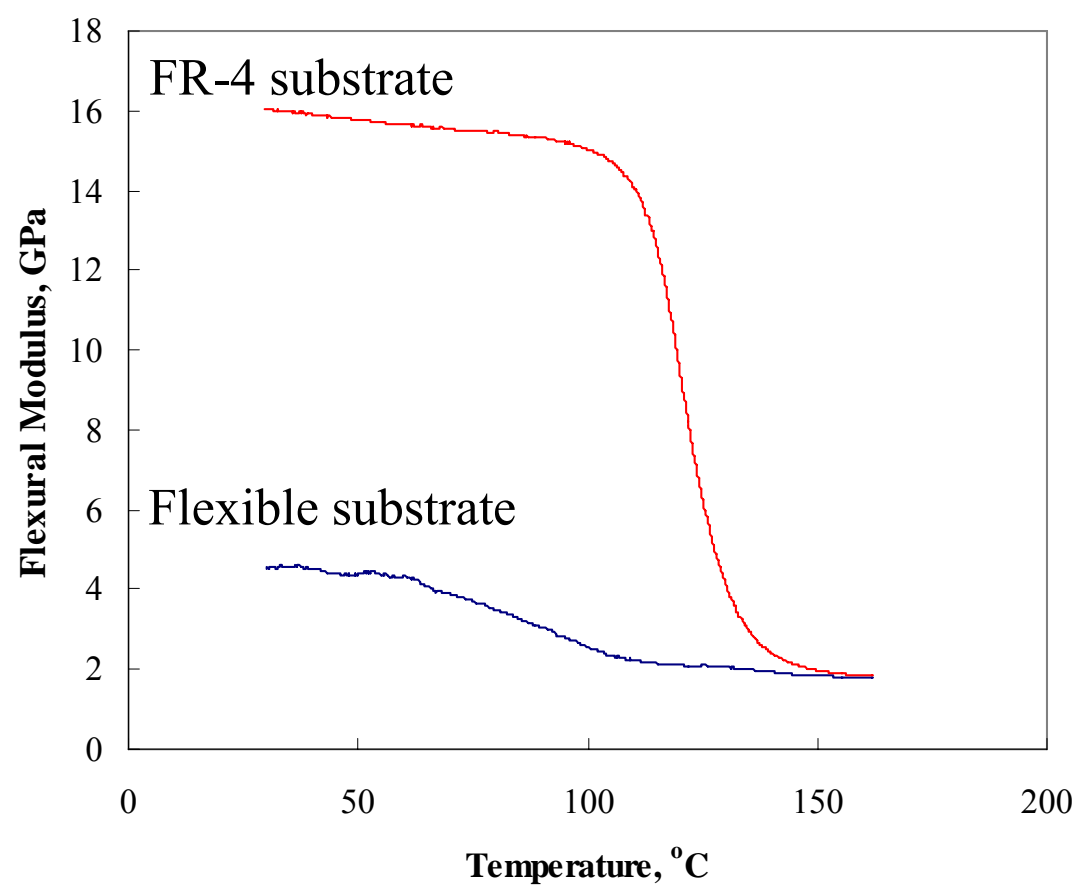

Figure 4 


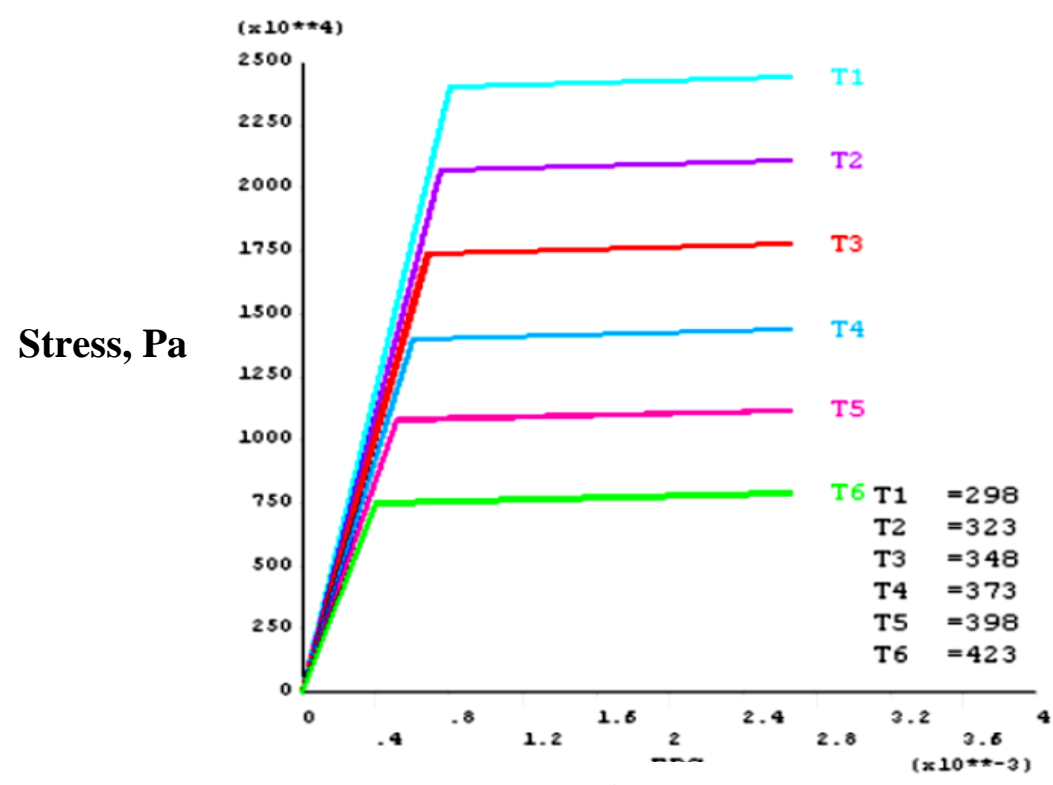

Strain

Figure 5 


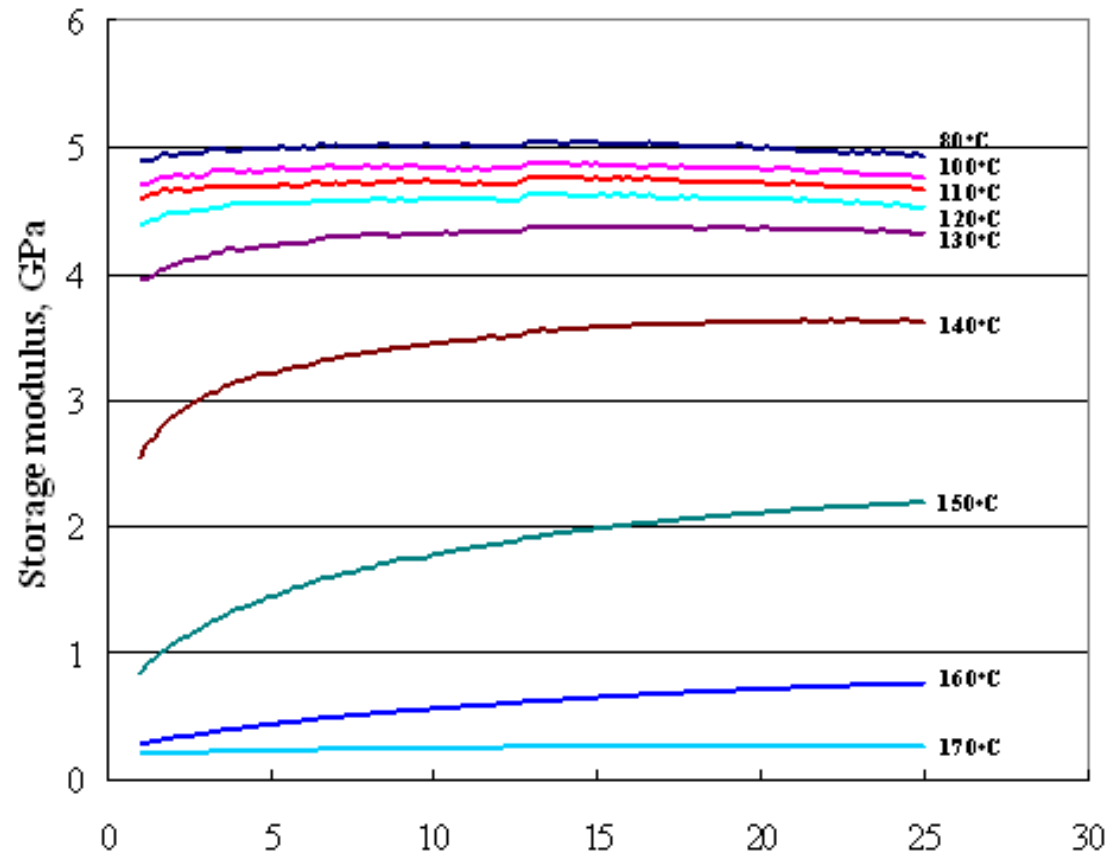

Frequency, $\rightleftarrows$

Figure 6 


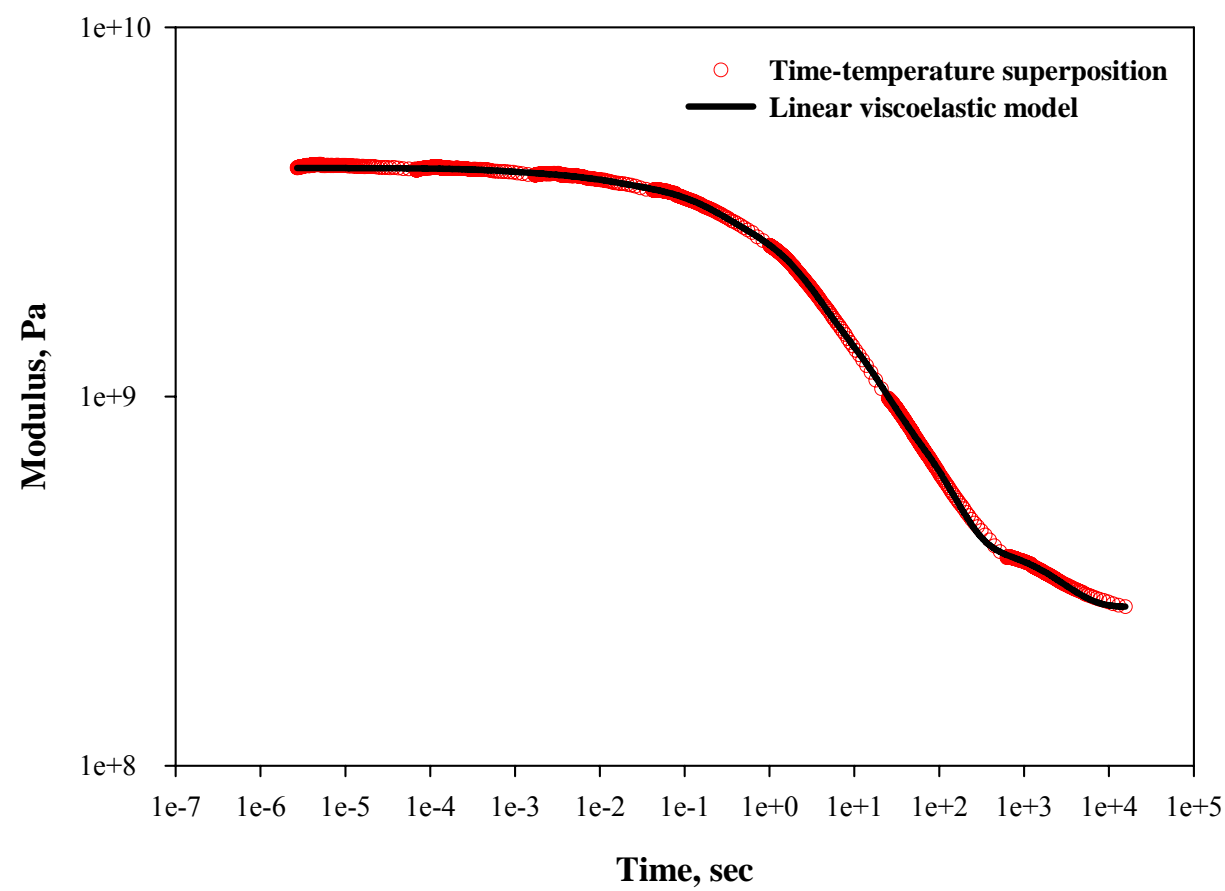

Figure 7 


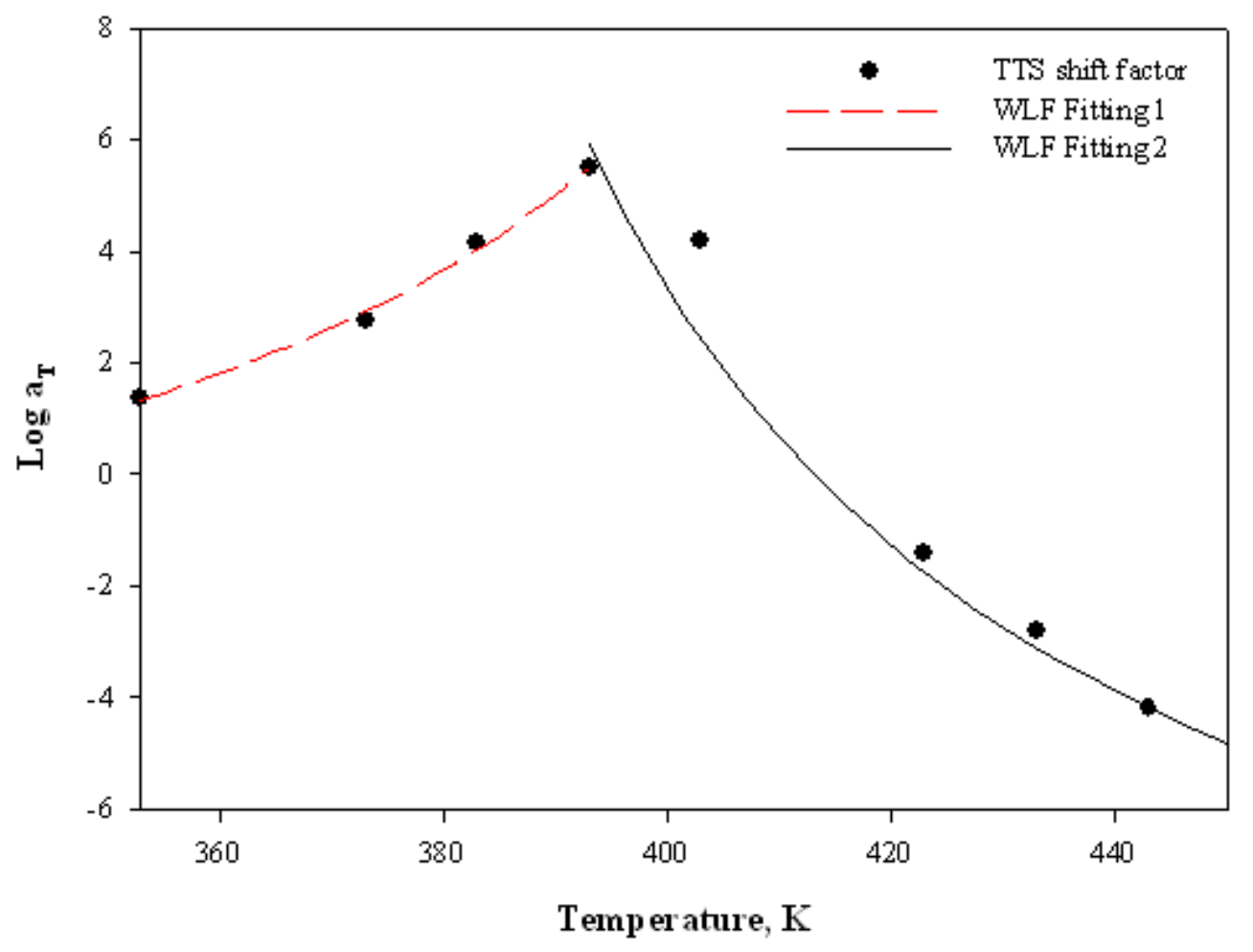

Figure 8 


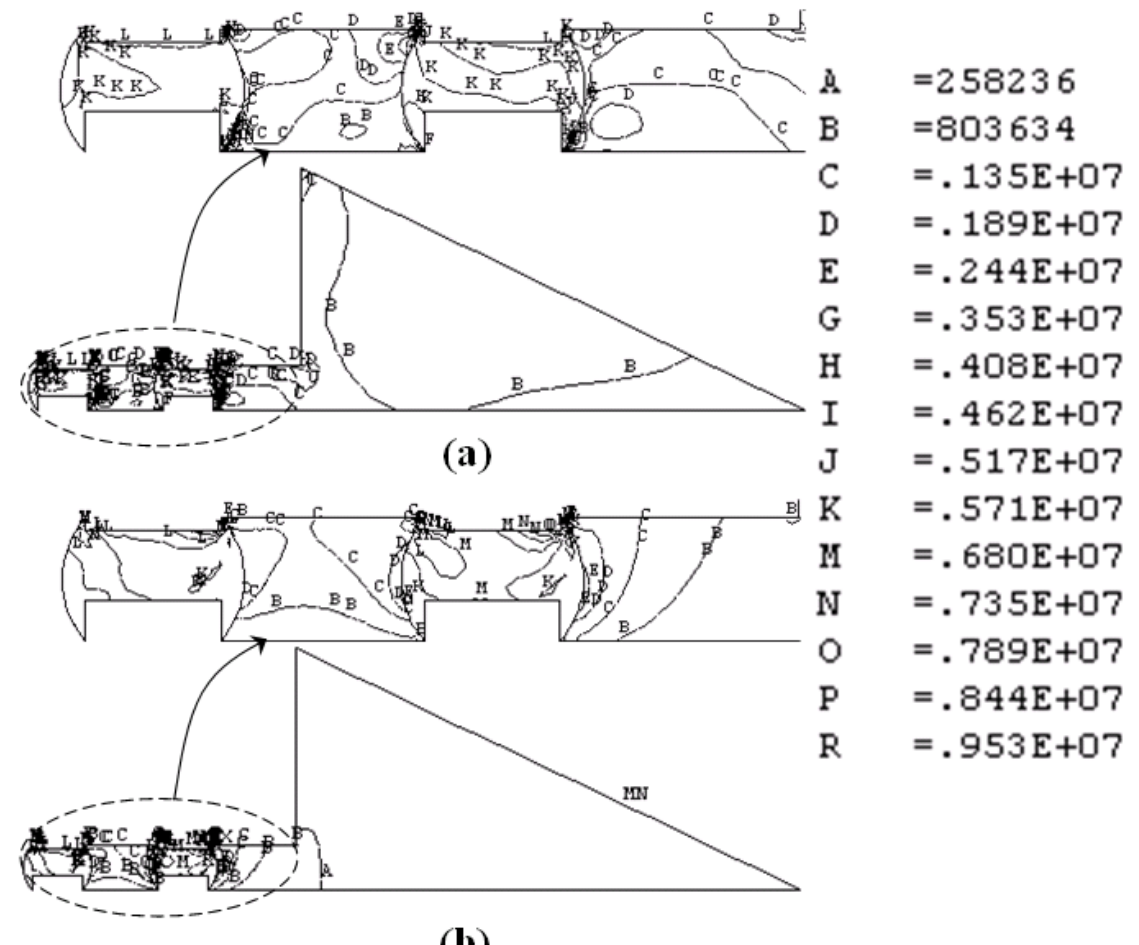

(b)

Figure 9 

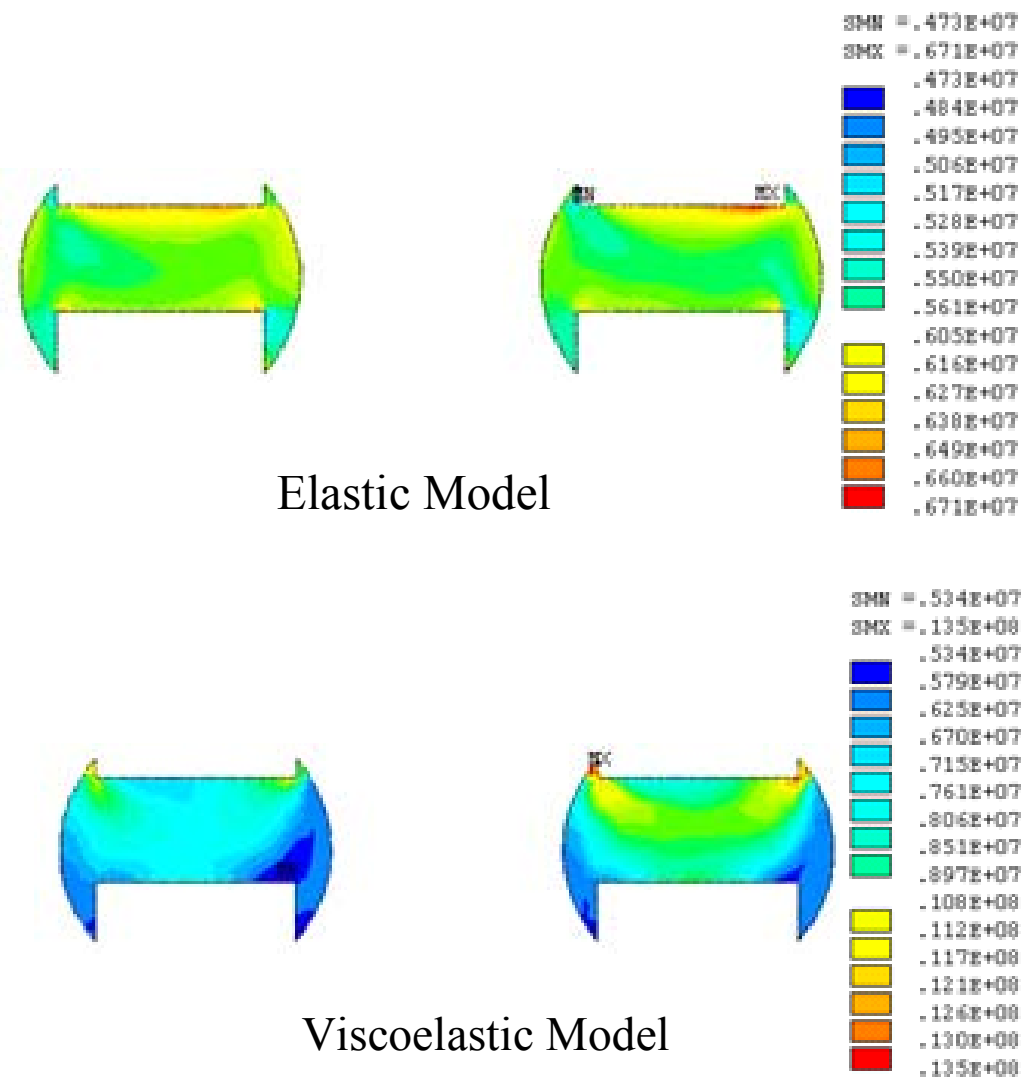

Figure 10 


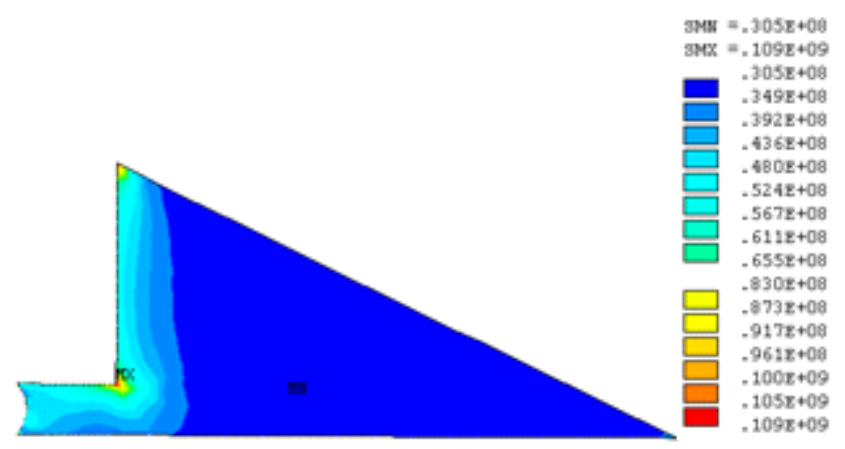

Elastic Model

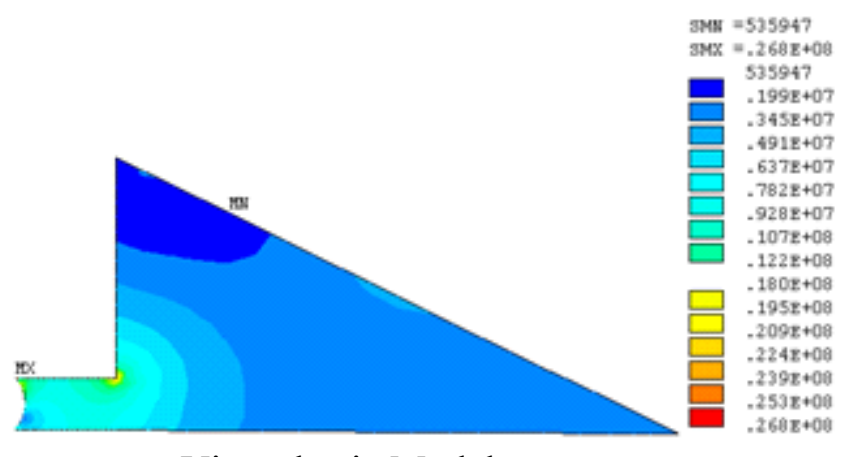

Viscoelastic Model

Figure 11 


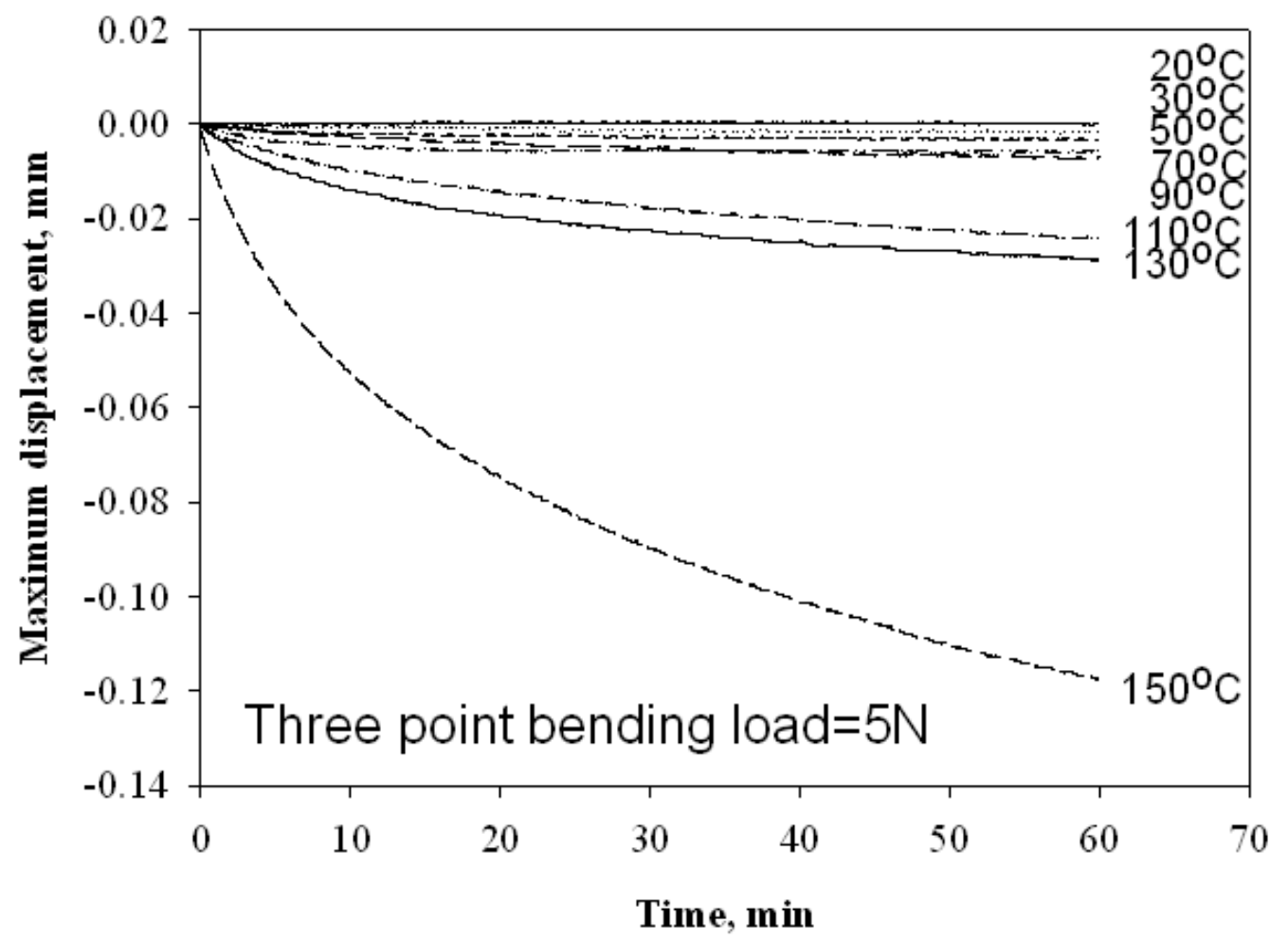

Figure 12 


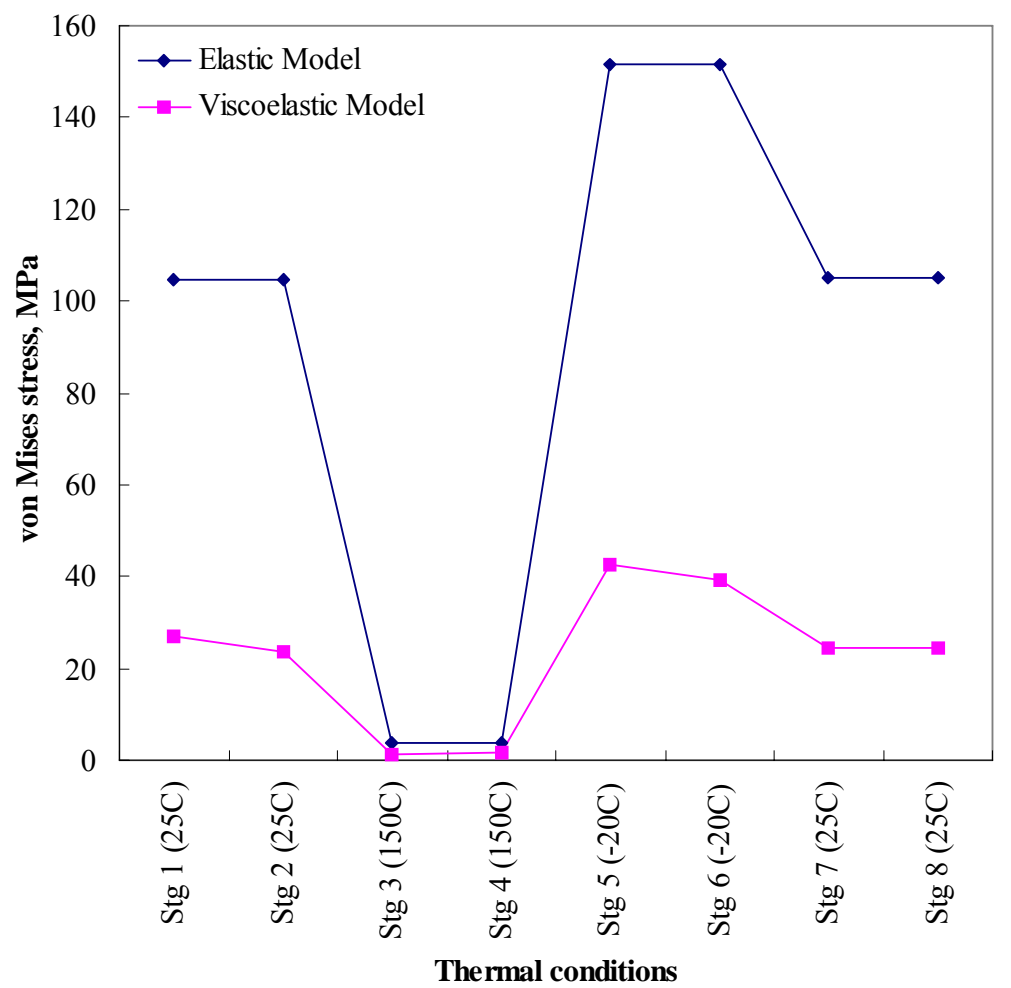

Figure 13 


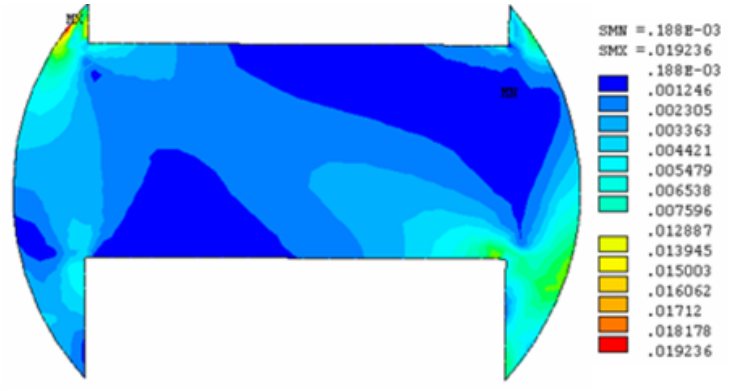

(a)

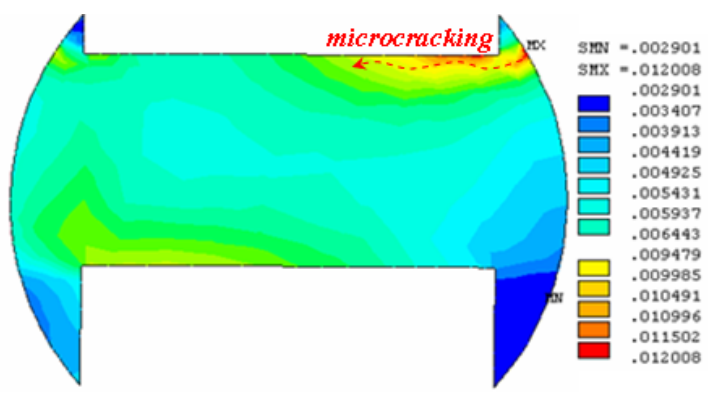

(b)

Figure 14 

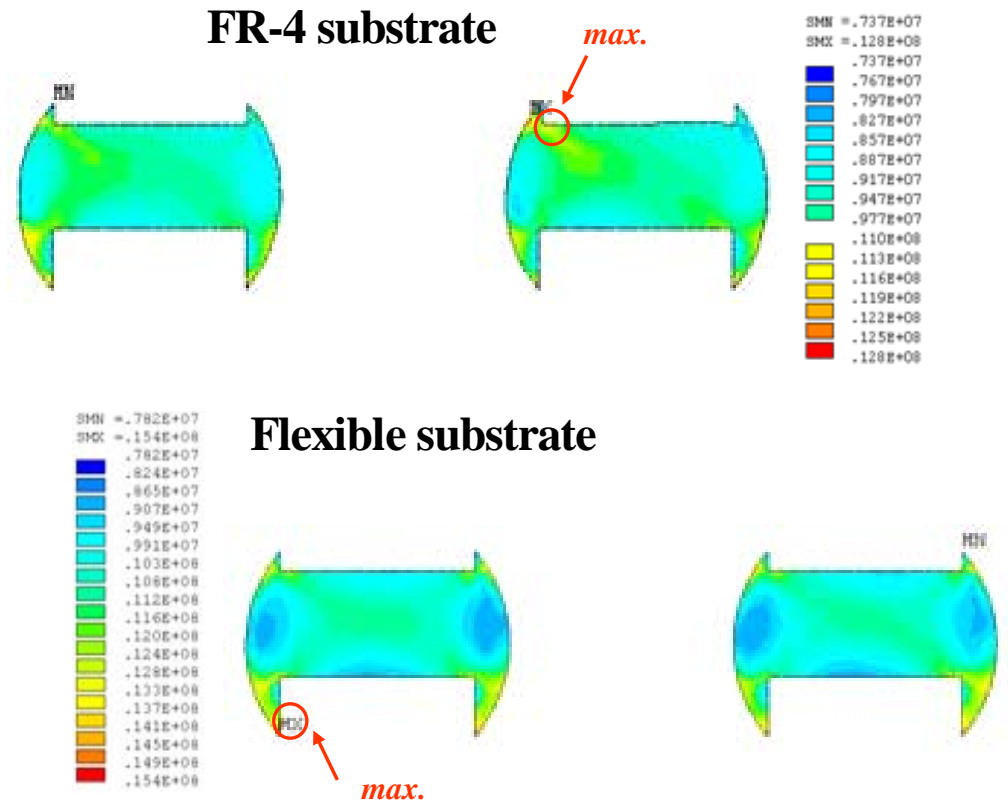

(a)

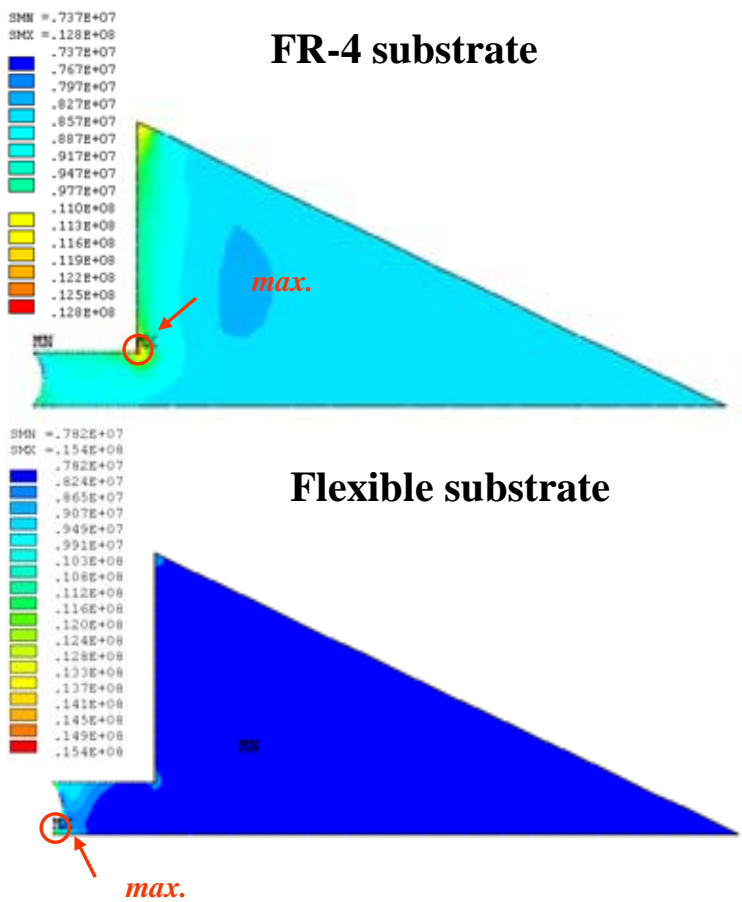

(b)

Figure 15 


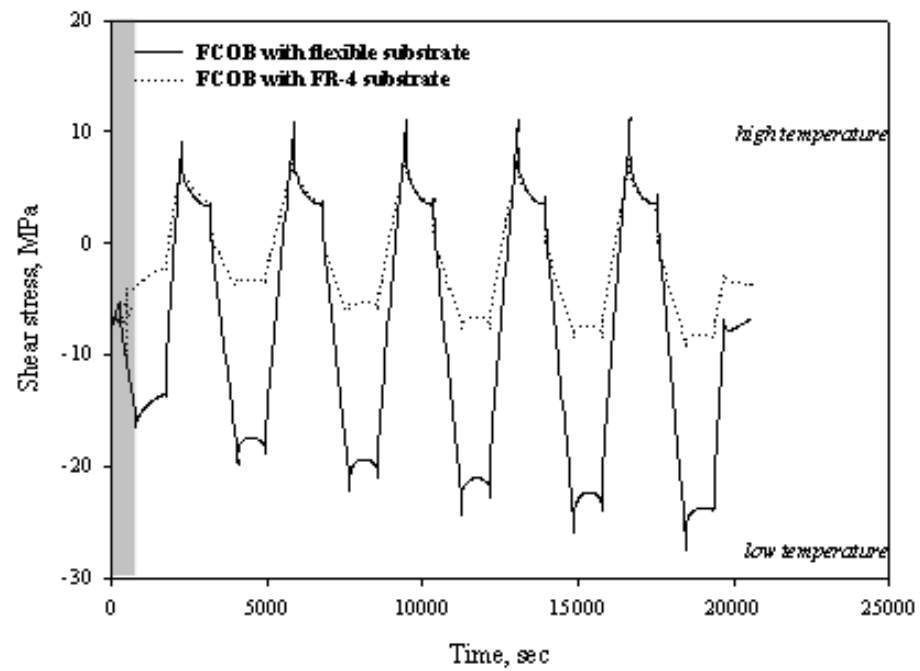

(a)

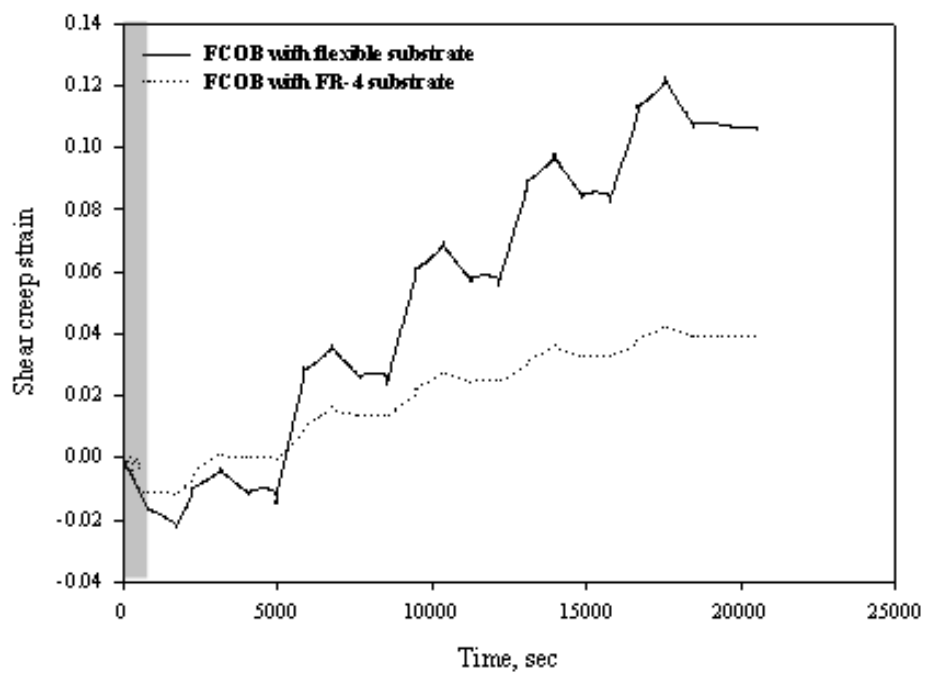

(b)

Figure 16 